\title{
Becoming Visible: Why We Should be Better Communicators Now
}

\author{
Alice Raffaele ${ }^{1}[1]$
}

Received: 18 June 2020 / Accepted: 21 December 2020 / Published online: 19 January 2021

(c) The Author(s), under exclusive licence to Springer Nature Switzerland AG part of Springer Nature 2021

\begin{abstract}
Several Operations Research (OR) applications have been presented at the $4^{\text {th }}$ AIROYoung Workshop in Bozen (February 5-7, 2020). We start this essay by reporting the main research topics studied and discussed nowadays by young OR researchers. Once again, these have shown the potential and the effect of exploiting applied mathematics, in particular OR, to solve problems arising from reality. Indeed, speaking about the present, OR has been already contributing to fight the COVID-19 pandemic from its beginning, integrated with other techniques to forecast and simulate future scenarios. For instance, OR can help decide how to optimally allocate resources and how to manage the supply chain of food, medical and essential items. We illustrate a few examples of the efforts done to tackle several aspects of the COVID-19 pandemic. Given its strong impact and wide applicability, we wonder about the visibility problem of OR: why is it still unknown to people and has not become a buzzword such as the terms "machine learning" or "artificial intelligence"? And, still, what does it mean to "become visible"? We compare some search terms with Google Trends and report several opinions on this topic. The main purpose of this essay is to refuel the discussion on OR communication to laypeople, by highlighting issues while considering different contexts. Starting from our young community itself, we would like to encourage researchers to take action to make OR more visible.
\end{abstract}

Keywords AIROYoung · OR applications · COVID-19 outbreak · OR communication

Alice Raffaele

alice.raffaele@unitn.it

1 Department of Mathematics, University of Trento, Trento, Italy 


\section{Introduction}

Cities, like dreams, are made of desires and fears, even if the thread of their discourse is secret, their rules are absurd, their perspectives deceitful, and everything conceals something else.

Italo Calvino, "Invisible cities", Chapter 3

Published in 1972, Italo Calvino's "Invisible cities" [1] has become a classic book everyone should read, especially people who are interested in combinatorics. In fact, chapters are enumerated in a very peculiar and studied way. The two protagonists, Marco Polo and the ruler of the Mongol Empire Kublai Khan, dialogue about the main cities of Khan's kingdom. In particular, Marco Polo uses evocative tales to present streets, buildings and people of the different places, while Kublai Khan listens, fascinated and curious about his own world. The story lends itself to having many interpretations, and we have found one very suitable to our research world, that we are going to adopt as the main theme throughout this essay.

During our whole career of researchers, as beginners or experts, we assume the roles of communicators and listeners. In a given moment while visiting the cities of our world, each one of us can be a Marco Polo and all the others Kublai Khan. The next instant, the parts are reversed.

In fact, every problem can be thought of as a city to be explored, through all its roads and neighbourhoods; a strategy is just a way of traversing it or finding one of its secrets, maybe heuristically or in an approximate way, hopefully exactly. And hence literature is the memory of past attempts and results; our thirst for knowledge becomes the desire of finding a breakthrough in lattices of streets, perceiving signs in the air and following hints left by the inner topology of the problem. Issues and details are the meeting places of our minds of researchers, where we exchange ideas and suggestions; they are squares where we connect with old and new colleagues which may give us indications or be also interested in travelling together for a while.

How many cities are there, in our world of Operations Research (OR)? We are lucky: there are so many that we may not be able to enumerate them all. Some problems of decades ago are still rising against our efforts, but as time passes new problems are being born. Throughout the years, cities have changed, and so have problems: latest variants and advanced applications are new buildings to enter and spots to go round; skyscrapers offer new points of view; our care for sustainability is like seeding trees, plants and maintaining parks. What remains unchanged is the fact that, directly through our eyes or indirectly by enchanting words of others, cities and problems are made to get lost in, without any fears.

Under this paradigm, conferences are organized events that may involve one or several cities; festivals to enjoy, where we get the chance to continuously switch between the two roles of communicators and listeners. In such occasions, we have the opportunity to discover new towns and routes, to see our and other problems through creative and enlightening perspectives. Even if we think we know every secret path of our city, there may always be another shortcut we have not considered. 
Thus, we should take notes of what captures our attention, during expositions and talks, and that is why we should not forget to put a travel note in our knapsack (well, actually this could be another problem itself).

With the contribution of us all as Marco Polo, we maintain the atlas of our discipline up to date; allowing ourselves to be Kublai Khan and to listen to others, we always leave this book open, willing to hear descriptions of problems through different voices.

Since this special issue is dedicated to the AIROYoung experience, we begin this work describing the little but enthusiastic contribution to the OR atlas given by the participants of the $4^{\text {th }}$ AIROYoung Workshop [2]. Then, we present some possible applications of OR to manage issues and aspects related to the COVID-19 pandemic. Despite its strong impact and wide applicability, we reflect on the fact that OR is still unknown to the public, compared to other disciplines. This visibility problem of OR is related to its communication to laypeople. The main purpose of the essay is to refuel the discussion on the topic, by highlighting issues and reporting opinions from the OR community, while considering different contexts. Little by little, AIROYoung has started to care about the topic and experiment during its workshops or through its social media accounts. We hope this essay could encourage other researchers to take action to make OR more visible.

\section{Adding a Page to our Atlas: the $4^{\text {th }}$ AIROYoung Workshop}

For those who pass it without entering, the city is one thing; it is another for those who are trapped by it and never leave. There is the city where you arrive for the first time; and there is another city which you leave never to return. Each deserves a different name.

Italo Calvino, "Invisible cities", Chapter 8

Each conference, workshop or meeting is like publishing the next chapter in a sort of Lonely Planet guide of our research world. Talks and lectures will be the subjects of the lines to write down, interleaved by questions and answers, suggestions and references.

One does not have to be a full or emeritus professor to have the chance to add such pages. With modesty and a lot of enthusiasm, the AIROYoung Researchers Chapter [3] of the Italian Operational Research Society (AIRO) [4] has been writing its own pages on the atlas of OR from 2016, when it was founded. The last one has been added during our $4^{\text {th }}$ AIROYoung Workshop in Bozen (February 5-7, 2020) on the topic "New advances in Optimization, Machine Learning and Data Science" [2]. About fifty people attended the event to discuss several themes, from pure and applied research to divulgation, with multidisciplinary connections. One main question was stirring in the rooms and corridors of the Free University of Bozen: what are young researchers' interests? Or, in accordance to our analogy, which cities are they exploring and dedicating their time, thoughts and energies to? 


\subsection{On the Road}

Among AIROYoungers' research subjects, there are classical evergreen and innovative modern problems, with care both to theoretical aspects and to practical applications, paying attention to companies' interests and actuality [5] (see Fig. 1).

For instance, what could maths do to contribute to sustainability (see [5], pages 12-15, 19-20, 24-25)? Quite a lot. Many companies are investing in renewable sources. OR can be utilized to improve the quality of air, developing methods to exploit solar radiations and wind speed to produce energy, rather than fossil fuels. Optimization models can be designed to promote the switch from grey coal to green renewables-based power systems. Indeed, the wind energy field has been the subject of several talks by AIROYoungers. Deciding where to locate the offshore turbines, how many and their interconnections with cables, can lower the impact on the environment, beyond helping companies to save money, for instance building the first wind farms subsidy free.

Circular economy can inspire the development of integrated decision systems based on data and analysis techniques, to optimize the operations of a logistic and waste recycling center. Materials are collected by the company trucks fleet and then separated to be converted into secondary raw materials.

Consider then mobility: have you ever missed any buses at a stop and needed for another to come? OR can be applied to the city public transportation system, to arrange buses at stops, to make transfers easier and/or to balance intervals between subsequent buses. Other projects related to public transportation include the investigation of the full conversion of a public bus fleet to zero-emission propulsion technologies and the combination of simulation and optimization for traffic disturbance recovery in a busy metro system. These aspects impact not only on economics but also on people's life quality and on the health of our planet.

Another class of problems studied from the beginning of OR is transportation (see [5], pages 8-10, 15, 32), which has adapted and changed throughout the decades but still finds new sectors to be applied in. Some AIROYoungers are interested in the management of freight transportation, organizing truck trips to minimize the travelled distance, taking into consideration vehicles capacities and delays on deliveries. Locating transshipment facilities (e.g., intermodal hubs) is another challenging question to deal with.

In the maritime sector, we can model the problem of liner and container shipping with large networks. OR can be used to create schedules that minimize the o

verall staying time of the vessels in the port, while ensuring that the operations of loading and discharging cargos are correctly carried out. Optimization can play in the negotiation between the shipping company and the different terminals. Moreover, several events may interfere in reality (e.g., bad weather or port congestion) preventing the original plan and causing postponements and malfunctions. Solving disruptions can be seen as a trade-off between minimizing both operational vessel and port call costs and the impact on cargos.

OR can be exploited to suggest possible recovery plans for decision makers. This also happens in the railway sector to improve reliability and make real-time adjustments on train schedules in a very few seconds. Handling trains arrival, 
departure and their assigned platforms is another interesting problem, while taking into account the topology of the stations and trying to minimize the weighted delays of trains.

Scheduling (see [5], pages 9-10, 14-15, 29, 37-39) is one of the most frequent themes among the works of the AIROYoungers, ranging from abstract problems to more concrete ones. For instance, given a set of already sequenced jobs, one could be interested in readjusting the schedule in order to improve the objective function value, maybe because of breakdowns or other constraints imposed by the company. Peculiar variants may evaluate whether a company would save money or not, when planning at a tactical level the tasks to be performed by a team of employees, before building their daily schedules.

And what about classical logistics inventory problems where a vendor has to deliver different products from different origins to a set of customers, maybe relying on a heterogeneous fleet of vehicles? Routing (see [5], pages 3, 8, 19, 24-25, 28-31, 34-35) has always been one of the favourite topics to study, minimizing depots, customers and transportation costs while satisfying demands and avoiding stock-out.

Considering the expansion of e-commerce, recently the focus shifted to lastmile delivery, which has been discussed by several researchers and also deeply by Claudia Archetti (ESSEC Business School, Paris) during her plenary lecture at the $4^{\text {th }}$ AIROYoung Workshop. When you order online, your item has been purchased, priced, picked (taken from the warehouse), packed, delivered first to the courier and then to you; all with the help of OR techniques, but the process is still evolving. Are we going to hire more occasional drivers exploiting crowd-shipping? These can decide to serve some customers by picking up the parcels either from the central depot or from an intermediate one. Compensation methods need to be designed to pay their service. Will same-day delivery become the new standard? Perhaps for the food market, but obviously, this is already expected from restaurants and shops that deliver prepared meals.

What seems inevitable is to take into account synchromodality, i.e., the synchronization of operations in supply chain, considering real-time information, cooperation and flexibility. Routing problems can be also tackled as routing games, crossing the border of Game Theory (see [5], page 36): we can also consider sociological aspects, such as measuring how much routing can be inefficient in a congested network, with respect to the social optimum.

OR can be integrated with techniques derived from other applied sciences, and also to solve problems with apparently different nature. This interplay with other fields has contributed to build new paths to explore. Another special guest of our workshop has been Tullia Padellini, a young Research Associate in Spatial Statistics and Epidemiology (Imperial College, London), who presented possible bridges between OR and Data Science (see [5], page 6). For instance, in Statistics some of the most used keywords are sparsity, robustness and significance, which have their own meanings in OR, but how far do they differ? Maybe not so much. Furthermore, OR can help in the development of a fitting procedure for Sparse Canonical Correlation Analysis, a dimensionality reduction method which allows consideration of multiple sources of data simultaneously. 
AIROYoungers exploit machine learning algorithms to predict donor responses to direct marketing campaigns, to tackle a probabilistic variant of the Travelling Salesman Problem, to approximate the gradient of a noisy function filtering with a Gaussian kernel.

The second invited speaker, David Pisinger (DTU, Copenhagen), gave a talk about optimization problems in airport baggage handling. Airports represent a big data optimization problem, to be studied with a mix of the tools in our knapsack: forecasting, data-mining, simulation, stochastic models. Optimally combining bookings and seats on flights is just one of the several challenges that characterize airports. One can also focus on the assignment of the baggage to proper gates, considering transits and distances between airplanes and facilities, or the allocation of racetracks, trying to minimize the number of missed bags per day.

But OR is not only applications: for instance it has intersections also with Graph Theory (e.g., colourings of cubic graphs - see [5], page 16) or one can rely on Computational Complexity (see [5], page 30) when proving the hardness of a problem. Being multidisciplinary is perhaps the most distinctive and relevant trait of OR, which allows us to study and reach several far lands, maybe simultaneously. We are experiencing what it means to be researchers and we couldn't prepare ourselves in a better way. Anyway, we should never forget good equipment.

\subsection{Our Survival Kit}

An explorer cannot go around without a set of proper tools. We are operations researchers: paraphrasing Virginia Woolf, one cannot think well, develop well, solve well, if one has not clear in mind well the features of the problem. To start our journey towards any city, the first indications we get are given through a textual

Fig. 1 Wordcloud of the titles of the works listed in the Book of Abstracts of the 4th AIROYoung Workshop [5]

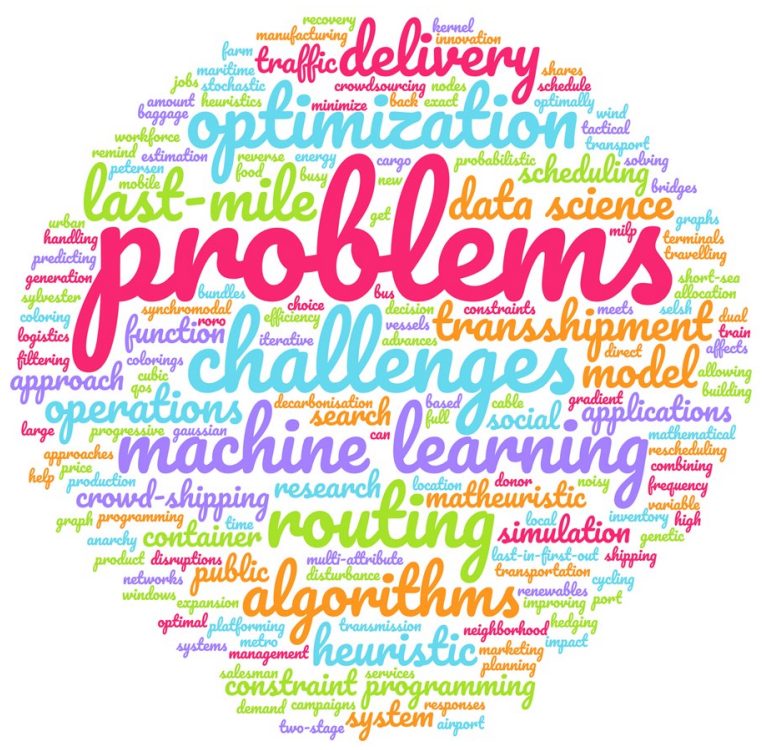


description of the problem, either in written or oral form. One of the skills always required and always to strengthen is modelling. Without being able to extract and abstract needed information, representing them in a more familiar and comfortable form such as the mathematical language, we would not take many steps from the door of our home.

Among techniques we find linear, integer, mixed-integer, quadratic, constraint and stochastic programming. They are essential to represent sets, parameters, decision variables, constraints and objectives, considering different levels of abstraction, being more or less adherent to reality. We observe that these techniques are a subset of the ones used by the wider OR community. Also, in their knapsacks, AIROYoungers have well-known exact methods, such as Branch\&Bound and Branch\&Cut, or metaheuristics such as Simulated Annealing, Variable Neighbourhood Search, Tabu Search and genetic algorithms, but they do not dislike to experiment, developing their own heuristics, greedy algorithms or mixing techniques from other fields, such as for example Petri Nets, regression, classification and neural networks.

Even if not mandatory, knowing at least one programming language can be lifechanging. Among the most preferred by AIROYoungers there are Python, $\mathrm{C}++$ and Java.

How not to put a Swiss army knife in a pocket? This is definitely a solver: Gurobi, CPLEX, SCIP, CP Optimizer and all the others offer us screwdrivers to get deep in the problems, awls to punch them and very sharp blades to cut them. And probably we'll discover other features we currently ignore or whose purpose is still hidden, only when we are going to need them.

\section{Emerging Cities: OR and the Metropolis of COVID-19}

With cities, it is as with dreams: everything imaginable can be dreamed, but even the most unexpected dream is a rebus that conceals a desire or, its reverse, a fear.

Italo Calvino, "Invisible cities", Chapter 3

This recurring analogy with cities can be applied not only to our field; in fact, OR may represent just a state in the continent of Mathematics; a state that borders with the pure Algebra, with the natural Economics and with the not so foreign land of Informatics, for instance. Other mainlands may be Biology, Chemistry, Physics, Medicine, etc.. Our traveller passports are full of stamps of different countries of this research world, interconnected thanks to globalization and to the inner spirit of Science. Travelling is our dream, as well as studying new problems. This imaginary world is quite different from our Earth, anyway, because cities may suddenly arise from the ground, shaking what we have built or even destroying our solid affirmations. But we are scientists and thus we also feel the advantages of these fearful events: we put together our efforts, wandering in very large groups.

This is exactly what has been happening since this February, when the SARSCoV-2 virus disrupted our lives with huge predominance: not a small city has emerged beneath our ground, but a wide metropolis denoted by COVID-19. And 
right away scientists in all fields have put aside their studies and projects to focus on what they could do for the whole community.

In the neighbourhood of mathematicians, the natural direction has been to go through the modelling streets, trying to collect, reuse and adapt existing models to understand the spread of the disease and predict what would have happened in the following days and weeks. Virologists focused on isolating the virus, while economists brought their attention to financial consequences of lockdown. Doctors, nurses and all medical staff have been overwhelmed by work. Everybody, even if inside its house or office, has tried to compute a way out or a policy to reduce the chaos of the COVID-19 metropolis.

OR researchers have not been still either. At the end of March, in less than a month from the outbreak of COVID-19 in Italy, Shen (2020) [6] published a survey on which OR and Industrial Engineering tools should be used to fight COVID-19, in each phase of the pandemic (i.e., prevention, during the outbreak, and recovery and post recovery). She suggested the integration of stochastic programming, when dealing with planning and uncertainty, with integer linear programming, game theory and network optimization approaches, in order to tackle specific problems. Among these we find locating COVID-19 testing facilities and designing their capacities, supply chain management of food and essential items, shortage of medical personnel, choosing designated hospital locations, patient triage, controlling admissions to hospitals and increasing testing ability.

In fact, governments should set up massive test programs, testing often and quickly to contain new virus clusters. Santini, who is a member and also one of the founders of AIROYoung, analysed the bottleneck problem of reagents availability, in order to check swabs with samples of saliva from tested people [7]. He showed how allocating reagents to laboratories and cross-regional collaborations can be optimized to increase the laboratories capacity. Lampariello and Sagratella [8] focused instead on the problem of deciding how many diagnostic tests each Italian region should perform to maximize the overall disease detection capability, defining a convex quadratic program and trying to improve the strategy adopted by the Italian health care system.

Patients may have different priorities according to their gravity. Perfectly on time, Ouyang et al. [9], published in February, investigated policies for making bed allocation decisions in an intensive care unit (ICU) of a hospital, during periods when patient demand is high. They analysed single-bed and multi-bed ICU scenarios, developed a mathematical model and proposed a heuristic to determine which patients should be admitted to the ICU, considering their chances of survival, the number of days they would have probably needed to stay and their health conditions. They tested several policies, among which First-Come-First-Served, Greedy Policy (which discharged patients the least likely to get worse) and Random Discharge Policy.

Prediction and simulation assume relevant roles in fighting COVID-19. Working together with the Spanish Commission of Mathematics, NeEds researchers BenítezPeña et al. [10] made seven-days-ahead predictions for the values of two variables of interest in Andalusia (Spain): the number of hospital beds and the number of patients in ICU. Data were collected online, cleaned and given as input to machine 
learning tools as Support Vector Regression, Random Forest and Sparse Optimal Randomized Regression Trees. To optimally combine the results of the three methods, they defined a quadratic constrained program to minimize the mean squared error of the observations and find the weights of each prediction. Once obtained the numbers for the following day, these are used as input to compute the values of the day after, and so on until the last day. Instead, to forecast the peak of the epidemic curve followed by the virus in Italy, Fenga and Del Castello [11] presented a compounded method which exploits two different paradigms: bootstrap techniques, from computer intensive statistical methods, and simulated annealing optimization.

During mass casualty incidents such as this pandemic, Emergency Medical Services (EMS) may not be able to send ambulances immediately to all patients, because of lack of resources. Thus, it becomes extremely important to develop dynamic response policies to match different types of ambulances (e.g., that offer basic and advanced life support) with low priority, high priority and critical patients, keeping into account that their conditions could deteriorate while waiting for service. DuBois and Albert [12] formulated the problem as a semi-Markov Decision Process to find optimal strategies, minimizing the penalty due to the decreased quality of service incurred by queued patients. Surprisingly, allowing for ambulances idling produces better results than dispatching immediately all available resources.

Doctors and nurses are constantly exposed to the risk of catching COVID19, due to the possible lack of sufficient personal protective equipment. This has an impact on the whole medical staff, since anyone who has been infected must stay in quarantine for a certain period of time (e.g., at least 14 days in Italy) and others may be then forced to work overtime. Standard scheduling tools do not take this into consideration, thus it can be relevant to optimally schedule, for instance, nurses' shifts, allowing them to work extra hours and, at the same time, balancing workloads and excessive stress. Seccia, another AIROYounger, proposed a mixed integer formulation of this problem that guarantees the minimum level of assistance required to patients while optimizing an objective function such as the overall number of hours worked by each nurse [13].

Even if related to generic disasters, Nagurney et al. [14] can also be applied to pandemics. They proposed new directions for research in disaster relief, in particular on the competition among humanitarian organizations in pre- and post-disaster operations. Integrating uncertainty with game theory and policy interventions, they developed a stochastic generalized Nash equilibrium model involving multiple humanitarian organizations, purchase locations, hubs for storage and freight service provision options and points of demand. Each humanitarian organization tries to maximize its expected utility and competes with others for financial donations and considering costs, solving a two-stage optimization problem to determine quantities of storage and delivery handling different disaster scenarios.

Working in OR means also being able to see connections and patterns between apparently different problems, exploiting again successful ideas. Fischetti et al. [15], which include another member and founder of AIROYoung, studied the social distancing problem, analysing the parallelism with the problem of optimally 
designing the layout of a wind farm. In fact, they juxtaposed the interference function of wind turbines due to wake effects and the infection function around customers because of the spreading of the virus. They defined the interference function with alternative formulations and compared them on simple cases. Using solution approaches designed for wind farms, they produced optimized facility layouts and applied them to restaurants and beach umbrellas.

These are only a few examples of what the OR community has done in these few months regarding the COVID-19 outbreak. Indeed, countless are the applications of OR to manage any optimization problems defined to handle this pandemic. We also mention the specific web-pages developed by known worldwide associations such as INFORMS [16] and The OR Society [17], by other national societies such as AIRO [18], and by universities and research centers such as MIT Operations Research Center [19]. Moreover, several journal special issues have been announced (see, e.g., [20-22]).

\section{Where is OR?}

I speak and speak, but the listener retains only the words he is expecting. [...]

It is not the voice that commands the story: it is the ear.

Italo Calvino, "Invisible cities", Chapter 9

Despite all the incredible and stunning results it could get in these decades, still OR is almost unknown to the public. On the contrary, other buzzwords have been spreading more and more, such as machine learning, big data or Internet-of-Things. Often, what is on people's mouths is a simplification, an intuition behind the true concepts which exploit information and digital technologies. The news talk almost every day about some "new artificial intelligence" believed to do something magical; algorithms have become so woven with our lives and people usually do not even ask how these work: they are satisfied with what algorithms do and what algorithms can be applied for, beyond making money. OR has nothing less than all of those: its potential is wide and large as we have seen in the previous sections; yet, when one says "Operations Research", very few understand (actually, almost nobody, unless they have studied Mathematics, Engineering or similar). But why does it happen? Where is OR?

Google Trends [23] allows us to compare up to five groups of search terms at one time and up to 25 terms in each group. Specifying the period and the geographical area, we can figure out what people are interested in while surfing the net. In particular, we compared the search term "operations research" with "machine learning", "big data" and "data science". We noticed that using "operations research" is basically the same as typing "operational research" in terms of the results, but the former performs slightly better. Moreover, we excluded the search term "analytics" because it can have several different meanings based on the topic (e.g., it is also used to indicate statistics and information, interpretations and communication of patterns in data). 


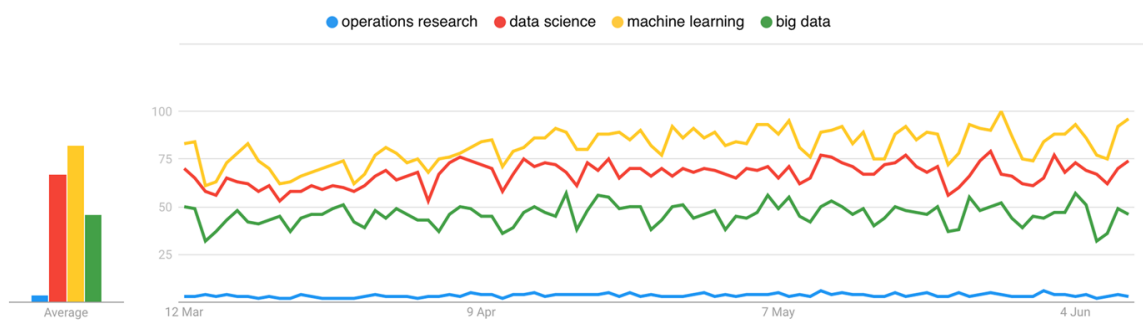

Fig. 2 Interest over time in the period March 12 - June 12 (source: Google Trends)

Figure 2 shows the trends for the above search terms, during the last 90 days and worldwide. The numbers represent search interest relative to the highest point on the chart: a value of 100 is the peak popularity for the input terms; a value of 50 means that the term is half as popular; a score of 0 means that there is not enough data for that term. Even if the comparison is in relative and not absolute terms, we can observe that OR searches are constant and low throughout time.

Figure 3 shows the interest in the different countries and unfortunately OR cannot be seen, hidden by the other more prevalent terms.

Among the 25 queries related to "machine learning", we find "covid 19 machine learning" and "coronavirus machine learning" at the $3^{\text {rd }}$ and $4^{\text {th }}$ places respectively, the former search increased by $1100 \%$ and the latter by $400 \%$ during the time horizon. Also "big data" has a query related to coronavirus, at the $7^{\text {th }}$ in the rank and increased by $200 \%$. Instead only 2 related queries are reported for "operations research" (i.e., "operations research uni due" and "operational research"), neither one of them mentioning the pandemic in progress.

Focusing on social networks and specially on Twitter, where the OR community is very active, we can check how several hashtags perform by exploiting web platforms such as RiteTag [24]. In Figure 4 we compare "\#orms" (i.e., the most used hashtag by OR community), "\#operationsresearch", "\#machinelearning", "\#datascience" and "\#bigdata". Results provided by RiteTag show the total number of posts on Instagram and the hourly number of tweets, retweets and visualizations on Twitter. These statistics vary according to the hour, in fact, they are obtained through a weighted average of the number of posts in the last hour (more significant), in the last 24 hours and, to a lesser extent, in the last 30 days. Also here, OR is not as popular as the other three disciplines.

Fig. 3 Interest over time compared breakdown by region (source: Google Trends) operations research data science machine learning big data

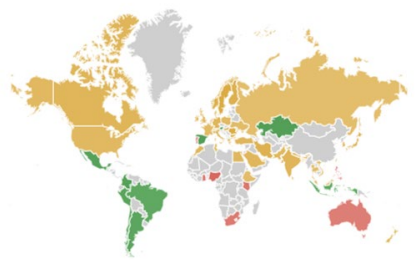




\section{Use these hashtags to get seen now}

\begin{tabular}{|c|c|c|c|c|c|}
\hline 只 & \#machinelearning & $617.0 \mathrm{k} 0$ & $154 \geqslant / \mathrm{h}$ & 346 七//h & $3.3 \mathrm{~m} \odot / \mathrm{h}$ \\
\hline $\mathbf{a}$ & \#datascience & & $121 \vartheta / \mathrm{h}$ & 283 ৫マ/h & $2.8 \mathrm{~m} O / \mathrm{h}$ \\
\hline $\mathbf{0}$ & \#bigdata & $655.5 \mathrm{k} 0$ & $104 y / h$ & 296 Łマ/h & $2.7 \mathrm{~m} O / \mathrm{h}$ \\
\hline
\end{tabular}

\section{Use these hashtags to get seen over time}

\begin{tabular}{|c|c|c|c|c|c|}
\hline 田 & \#orms & 31.7k@0 & $4 \geqslant / h$ & 0 セマ/h & $25.7 \mathrm{k} \odot / \mathrm{h}$ \\
\hline a & \#operationsresearch & & $0 \geqslant / \mathrm{h}$ & 4 セマ/h & $0.0 \odot / h$ \\
\hline
\end{tabular}

Fig. 4 Hashtags comparison results for June 12, h 16:30 (source: RiteTag)

These charts and numbers are not proofs, but they are for sure indicators that OR is still remaining invisible, even being quite used. For instance, people are shopping online more and more, receiving their goods at home; when they book a plane ticket, they are offered the possibility to choose their preferred seating, by paying some fees accordingly. Still, they are usually unaware that there may probably be OR behind both situations. This lack of visibility has long been a source of concern to OR professionals. In 2001, Pidd [25] described the two main paradoxes of this discipline: "OR is neither young nor old and, despite its widespread use, the visibility of $O R$ in the public eye is very limited". In 2004, Eisner [26] stated that OR "is probably the most important field nobody' ever heard of'. Power et al. [27] reported that the concepts of OR and management science may have been replaced by "Business Analytics", used as a synonym. Well, being invisible is not always a defect: Norman [28] declared that the best technology is the one that becomes invisible, focusing on simplicity, pride of ownership and joy of use. Users should not worry or struggle about how a system is working because they only care about goals and results. But is this what we want for OR? Though we may appreciate the fact of being widely exploited, would it be enough? And, mostly, how can we make OR more visible? To answer these questions, we should first better formulate our problem, i.e., define what "becoming visible" could mean. We are so good at solving problems, why shouldn't be able to tackle this one?

\section{Becoming Visible, Now}

Perhaps everything lies in knowing what words to speak, what actions to perform, and in what order and rhythm; or else someone's gaze, answer, gesture is enough; at that moment, all spaces change, all heights, distances; the city is transfigured, becomes crystalline, transparent as a dragonfly.

Italo Calvino, "Invisible cities", Chapter 9 
The main purpose of this section, and actually of the whole essay, is to refuel the discussion on the topic of OR visibility. Throughout the decades, a lot of work has been done to promote OR. Unfortunately, much of the material is not readily available in the published literature. Anyway, we can consider some interpretations of "visible" and define a few possible contexts, by specifying the related target audiences, what may be the main objectives and how these can be reached. Then, this part reports some observations on OR communication and focuses on the key aspects to be considered.

\subsection{Different Contexts, Different Interpretations}

As the first context, consider industry. Enhancing OR visibility to companies can mean promoting the application of OR techniques to real-world situations that need to be optimized. Indeed, OR can offer as powerful tools as machine learning and artificial intelligence, and these do not have to be alternative but rather synergical. In this case, maybe it is not so relevant that people understand what OR really is; it would be more effective to make companies understand what OR can actually do, opening CEOs' eyes to further applications. Using the OR label would not be required. Indeed, "a rose by any other name would smell as sweet" [29]. To this purpose, the absorption by other labels, as defined by Pidd [25], could be acceptable, even if the main risk would be not to fully credit OR of its merits. OR practitioners employed in the industry would be the ideal communicators to expose to CEOs the potential achievements of OR. They would get their expertise widely taken up by managers. Here, one possible skill could be to be able to exploit OR interplay with other disciplines, adapting to the latest trend influencing the industry, in order to sell OR contents, implicitly or explicitly.

A recent example in the industrial context are the activities done by the EURO Working Group on Practice of OR (EWGPOR) [30], launched in 2015 and now composed of almost 200 members from all over the world. The initiative "aims to enable OR professionals to have more impact on the outside world, by helping them find solutions to typical practical challenges, gain understanding of tools/ techniques they haven't used before, build their networks, and learn from others in order to inspire and expand their own practice". Moreover, the working group members of EWGPOR aim to enhance the cooperation between practitioners and academics. They participate in conferences (e.g., the "Making an Impact" stream during EURO 2019 [31]), organize meetings, seminars and online events too (see EWGPOR Twitter account [32] for further details). On the related website [30], one can find case studies and interesting links, such as the one to The OR Society's "Impact Magazine" [33], a free magazine that presents real-world examples of how to use analysis to make better decisions. The last meeting of EWGPOR, originally scheduled in March 2020, was postponed to the end of September and eventually held online [34]. In particular, it consisted of two half-day sessions, followed by a series of one-hour webinars every Monday from the 5th October to 2nd November. Beyond keynote talks, also parallel discussion groups were organized. One of these 
was especially dedicated to the topic of OR promotion, where the need to improve awareness of OR both to OR professionals and general people was underlined.

Instead, the OR label should be explicitly adopted when introducing the discipline to students. In this case, fostering OR visibility means to uncover a specific branch of applied mathematics in order to increase students' motivation towards mathematics and all other STEM disciplines. Also, showing practical uses of mathematics in daily situations may help not to be scared of it. Moreover, another goal may be to inspire young people to pursue a career in scientific fields and, in particular, in OR. Students' interest, in particular at lower schools before University, can be enhanced by participating in workshops, seminars or other OR-based activities. Actually, not only students but also teachers should be considered as possible recipients, through, for instance, ad hoc training courses. In fact, teachers may become the future communicators of OR, reaching a wider audience throughout the years, by presenting OR to their classrooms and, why not, to their colleagues too. Furthermore, beyond OR topics, historic OR figures can be presented such as George Dantzig, Delbert Ray Fulkerson, Ailsa H. Land and Alison Grant Harcourt, to encourage both girls and boys.

The OR Society and INFORMS have been promoting OR to teachers and younger students for decades now, with the OR in Education project [35] and the INFORMS Resource Center [36], respectively. Several initiatives have been developed over the last thirty years, including workshops, seminars, teaching units and competition. For more details on OR educational activities addressed to Grades 9-12, the interested reader is also referred to Raffaele and Gobbi, "Teaching OR before University: a focus on Grades 9-12"' (submitted).

Finally, as the third and last example, we consider government institutions as target audiences. Unfortunately, not always national or local OR organizations are well-known as international societies such as The OR Society or INFORMS. They should aim to be more visible, i.e., in terms of recognition by governments. In fact, being more recognized may lead obtaining support and funding for research activities, as well as to be taken into account when governments make decisions. These can be improved by OR; indeed, it can be applied to problems such as urban and air transportation, natural resources management, homeland security and safety risks, military systems, deployment of police, fire and emergency units, but also voting systems, and sports (for further details, see [37]). Thus, also in this context the OR label should be adopted explicitly, without being absorbed by any other discipline. Ideal communicators may be, for instance, presidents and counsellors of associations and societies.

Possible ways of illustrating the OR potential are sponsoring presentations and conferences, collecting publications and showing success stories, as done by INFORMS with the "Public Sector OR" section [38] and the page addressed to policymakers [39].

\subsection{On OR Communication}

In 2015, Brixius [40] wrote that OR is an indispensable tool of industry, but has never really connected with the technology community in the way it deserves, and 
that may be its fault. The interfaces we adopt to present OR may be too intricate, software developed for specific and peculiar problems. "Practitioners will pick up OR tools when they are easier to use and general purpose.". Recently, Rothberg [41] agreed: OR applications are usually exploited to address highly complex, largescale business problems that are not tangible to most people as other technologies such as machine learning. People may be scared away with too much technical details. Lübbecke [42] suggested that we are "too complicated". He reported the story of Randal Olson, an AI researcher who, starting from a procedure developed to compute the optimal search strategy for Where is Waldo?, implemented in 2015 his own genetic algorithm, in order to obtain an optimal road trip to visit each U.S. state and D.C. [43]. Exactly as the original problem studied by Dantzig et al. in 1954 [44]. But Olson's work was promoted in an article of The Washington Post [45] that made appear an instance with 49 cities as very large to solve, while not mentioning a single word about the deep study of TSP done in OR in all these years (e.g., see Applegate et al. [46]). Apparently, OR is not taken into account, but we know and we have shown in the previous sections that OR can have a relevant role in tackling several problems arising from industry or everyday life. OR can empower companies to exploit their data to make better decisions. Moreover, through the years, data availability and quality has been increasing. As Bixby recently commented [47], "At the highest levels of companies, there is an awareness of the importance of being able to understand data and use it to make the best possible business decisions (which is precisely what mathematical optimization does)".

\subsection{What We Should Care About}

So, what can we do? When we write something and specially mathematics, we should have a specific reader in mind [48]; the same when we communicate. We do not want to lose our listeners along the lines of our work because our phrases appear too boring, confusing or intricate. To communicate and divulge OR, we should first understand our audience and the context, and then choose our words properly, without sounding complex or out of reach. We must always take into account that our target audience may not possess the needed background to get and evaluate what we are saying, considering also possible misunderstandings. For instance, when we talk about optimization, even if it is a word people know, we should keep in mind that it may have several meanings, based on the specific field of mathematics, to common sense or other possible connotations.

We could and should try to simplify our arguments. Goulet and Lamontagne [49] suggested adapting the language by summarizing the main concepts to transmit in a limited amount of words. This may lead to removing some of the very specialized technical jargon, making the text more understable. But what is the right level of simplicity? Scharrer et al. [50] observed that laypeople can be hit by the easiness effect when reading easy texts. The easiness effect is the simplification of complex information characteristic of authentic popularized articles addressed to the general public. Despite being not trained or qualified in a particular subject, people can find persuasive the information provided. Moreover, they can over confidently rely on their own judgment, maybe underestimating the real complexity of the topic. 
Thus, some cautiousness becomes necessary. Determining how much to simplify may depend both on the message we want to transmit and on the qualification and expertise of our target audience, always considering the easiness effect.

Rather than simpler, we should aim to make our topics more flexible and adaptable. Among possible models of communication of science and technology, the contextual model is the one that acknowledges that people process information according to social and psychological schemas shaped by their previous experiences, cultural context, and personal circumstances [51]. Thus, their background, knowledge and objectives are relevant, and this is directly connected with the different interpretations of visibility seen in the previous section. Is our audience composed of CEOs and firms? Probably we should concentrate more on understanding their goals, identifying which OR techniques would be suitable and showing them the possible outcomes, sacrificing some precision if needed. Are we giving a talk to Grades 10-12 students? Let's provide them some preliminary details to grow their interest, not only theory and formulas, but maybe inspiring quotes or scenes from movies related to the topic we are going to present. Are we using Twitter, Instagram or other social media to spread our research? Perhaps a few keywords and colorful pictures are the way to go, to attract glances which may become interested readers, and hopefully users who share our posts. And perhaps social networks are the tool to bet on, to find a breakthrough in the visibility problem of OR. They are fast, easy to use and interact with; mostly, they can reach thousands or millions of people all over the world. Nowadays, companies and also policymakers and politicians exploit them to reach their customers and partners or their public. In particular, we should try to exploit more Twitter, where the OR community is very active, as we mentioned before. We could easily see and compare our attempts, as well as promote those ourselves. We should keep going in tweeting and sharing our \#orms posts, articles and initiatives, addressing specific individuals, wider communities or generic people. Moreover, Twitter would allow us to pay attention to the trends of the moment, either good or bad. For instance, in this critical period, each day people are tweeting thousands of posts with tags related to COVID-19. Perhaps this is the time when they are more willing (or need the most) to listen that some aspects of the global disease can be handled or even solved. This is probably why Nagurney's article on the stressed blood supply chain and the coronavirus, published in "The Conversation" on March 12 [52], is the most read one published over the past year by a University of Massachusetts Amherst faculty member, as she reports in her blog. She also promotes an INFORMS webinar on the topic of COVID-19 and supply chain, and adds a series of links to recent media interviews [53]. Is the OR label required, in this case? I would say so, but maybe not right away; capturing people's attention may be more relevant to start.

\section{Conclusion - Our First Steps}

This is the aim of my explorations: examining the traces of happiness still to be glimpsed, I gauge its short supply. If you want to know how much darkness there is around you, you must sharpen your eyes, peering at the faint lights in the distance.

Italo Calvino, "Invisible cities", Chapter 4 
The latest AIROYoung Workshop in Bozen (February 5-7, 2020) has allowed us to travel through several problems, exploring their definitions, analysis, developments and solving procedures. On the last day of the workshop, there was a session called "Pitch talks for 1st year PhD students", actually extended to all PhD students and postdoc researchers attending the workshop. First, they had to write down what OR means to them and for what purposes they use it. Then, all participants had exactly one minute each to present their projects to others, receiving suggestions and feedback from each other. The exercise was similar to the one proposed by Goulet and Lamontagne [49]; we called ours the AIROYoung Challenge. It allowed us to start to realize how difficult it is to summarize our research and highlight its very essential features, in order to communicate it to others, even our colleagues. We recorded and shared some attempts of the participants [54] through our Instagram [55] and Twitter [56] accounts, where we are very enthusiasts in promoting our research, events and achievements.

Since its foundation in 2016, AIROYoung has been caring about the visibility problem of OR. There is a lot to do to sharpen our eyes and to improve our OR communication, thus we'll continue experimenting disparate ways to tell our world. We have understood that our Kublai Khans can be very different. And according to the age and the identity of our listeners, we need to change our words and the tone of our voices, still trying to transmit the main message we have in mind. We are playing with their attention level, that is why we should move our eyes from problems and cities we are visiting and instead understand possible future tourists. What would they like to see? What would they like to hear? Based on their interests, competences and background, we should change what we are illustrating about our cities. Rather than just simplifying concepts, we should adapt them in accordance to who is listening to us and who we would like to reach. After all, we have an atlas full of pages to browse and share: there must be some topics our target audiences are more curious to explore.

Acknowledgements I thank the two anonymous referees for their precious advice that allowed me to better define and explain my work. I would like to also thank Martina Fischetti for her suggestions and support.

\section{References}

1. Calvino I, Weaver W (1978) Invisible Cities. A Helen and Kurt Wol Book. Harcourt, Brace \& Company. ISBN 9780156453806. https://books.google.it/books?id=5AokCxyISuIC

2. AIROYoung Researchers Chapter (2020) 4th AIROYoung Workshop: New Advances in Optimization, Machine Learning and Data Science. https://www.unibz.it/it/events/132924-4th-airoyoung-workshopnew-advances-in-optimization-machine-learning-and-data-science. Accessed 21 Oct 2020

3. AIROYoung Researchers Chapter (2016) Website. https://www.airoyoung.org. Accessed 12 May 2020

4. Associazione Italiana di Ricerca Operativa (AIRO) (1961) https://www.airo.org. Accessed 06 June 2020

5. AIROYoung Researchers Chapter (2020) 4th AIROYoung Workshop, Book of Abstracts. https:// www.dropbox.com/s/6c8c3lnbwbisr43/Bookofabstracts.pdf?dl=0. Accessed 22 May 2020

6. Shen S (2020) From Data to Actions, From Observations to Solutions. A Summary of Operations Research and Industrial Engineering Tools for Fighting COVID-19. http://www.personal.umich.edu/ siqian/docs/or-ie-fighting-covid19v1.pdf. Accessed 12 May 2020 
7. Santini A (2020) Optimising the assignment of swabs and reagents for PCR testing during a viral epidemic. Technical report, Universitat Pompeu Fabra https://santini.in/files/papers/santini-2020. pdf. Accessed 02 June 2020

8. Lampariello L, Sagratella S (2020) Effectively managing diagnostic tests to monitor the COVID-19 outbreak in Italy. http://www.optimization-online.org/DBHTML/2020/03/7680.html. Accessed 12 June 2020

9. Ouyang H, Argon NT, Ziya S (2020) Allocation of Intensive Care Unit Beds in Periods of High Demand. Operations Research 68(2):591-608. https://doi.org/10.1287/opre.2019.1876

10. Benítez-Peña S, Carrizosa E, Guerrero V, Dolores Jiménez Gamero M, Martin-Barragan B, MoleroRío C, Ramirez-Cobo P, Romero Morales D, Sillero-Denamiel MR (2020) Short-Term Predictions of the Evolution of COVID-19 in Andalusia. An Ensemble Method https://doi.org/10.13140/ RG.2.2.26256.23046

11. Fenga L, Del Castello C (2020) CoViD-19: Meta-heuristic optimization based forecast method on time dependent bootstrapped data. https://www.medrxiv.org/content/10.1101/2020.04.02.20050153v2.full. pdf. Accessed 12 June 2020

12. Dubois E, Laura AA (2020) Dispatching Policies During Prolonged Mass Casualty Incidents. University of Wisconsin-Madison, Technical report https://uwmadison.box.com/s/76w68dj1tn6mu3k6106dxv9vo3gov5qc

13. Seccia R (2020) The Nurse Rostering Problem in COVID-19 emergency scenario. http://www. optimization-online.org/DBFILE/2020/03/7712.pdf. Accessed 06 June 2020

14. Nagurney A, Salarpour M, Dong J, Nagurney LS (2020) A Stochastic Disaster Relief Game Theory Network Model. SN Operations Research Forum, 1(2) https://doi.org/10.1007/s43069-020-0010-0

15. Fischetti M, Fischetti M, Stoustrup J (2020) Mathematical optimization for social distancing. https:// www.researchgate.net/publication/341708793Mathematicaloptimizationforsocialdistancing. Accessed 02 June 2020

16. INFORMS (2020) Information on COVID-19 and Pandemics. https://www.informs.org/Impact/O.R.Analytics-for-Policymakers/COVID-19. Accessed 16 Oct 2020

17. The OR Society (2020) Coronavirus (COVID-19). https://www.theorsociety.com/get-involved/ coronavirus-covid-19/. Accessed 16 Oct 2020

18. Associazione Italiana di Ricerca Operativa (AIRO) (2020) COVID19: Risorse di AIRO per l'emergenza. http://www.airo.org/index.php/en/34-introduzione-airo/216-covid19. Accessed 21 Oct 2020

19. MIT Operations Research Center (2020) COVID-19 Projects. https://orc.mit.edu/impact/covid-19projects. Accessed 21 Oct 2020

20. Operations Management Research (2020) Call for Papers on Resilience in Global Supply Chains (GSCs): COVID 19 Outbreak. https://www.springer.com/journal/12063/updates/17978468. Accessed 16 Oct 2020

21. OPSEARCH (2020) Operations Research for Healthcare Systems Management: Modelling and Application. https://www.springer.com/journal/12597/updates/18157028. Accessed 16 Oct 2020

22. European Journal of Operational Research (2020) The role of Operational Research in the future epidemics/ pandemics. https://www.journals.elsevier.com/europeanjournal-of-operational-research/ call-for-papers/operational-research-inthe-future-epidemics-pandemics. Accessed 16 Oct 2020

23. Google (2020) Google Trends. https://trends.google.com/trends/?geo=US. Accessed 12 June 2020

24. RiteKit (2020) Rite Tag, Hashtag Comparison. https://app.ritetag.com/hashtagcomparison. Accessed 12 June 2020

25. Michael P (2001) The future of OR. Journal of the Operational Research Society 52:1181-1190

26. The Boston Globe (2004) Operation everything - It stocks your grocery store, schedules your favorite team's games, and helps plan your vacation. A primer on the most influential academic discipline you've never heard of. http://archive.boston.com/news/globe/ideas/articles/2004/06/27/ operationeverything?pg=full. Accessed 16 Oct 2020

27. Power DJ, Heavin C, McDermott J, Daly M (2018) Defining business analytics: an empirical approach. Journal of Business Analytics 1(1):40-53. https://doi.org/10.1080/2573234X.2018.1507605

28. Donald A (1998) Norman. MIT Press, Cambridge, MA, USA, The Invisible Computer

29. Shakespeare W, Gibbons B (2002) Romeo and Juliet. Arden edition of the works of William Shakespeare, Arden Shakespeare. ISBN 9781903436417. https://books.google.it/books?id=Lr97msKjD28C

30. EURO Working Group on Practice of OR (2016) https://www.euro-online.org/websites/or-inpractice/. Accessed 19 Oct 2020

31. EURO Working Group on Practice of OR (2019) Making an Impact - EURO 2019. https://www. euro-online.org/websites/or-in-practice/making-animpact-at-euro-2019/. Accessed 20 Oct 2020 
32. EURO Working Group on Practice of OR (2016) Twitter account. https://twitter.com/EwgPor. Accessed 19 Oct 2020

33. The OR Society (2015) Impact Magazine. https://www.theorsociety.com/publications/magazines/ impact-magazine/. Accessed 20 Oct 2020

34. EURO Working Group on Practice of OR (2020) EWG-POR 2020: Challenges in the deployment of OR projects. https://www.euro-online.org/websites/or-inpractice/ewg-por-2020-challenges-in-thedeployment-of-or-projects/. Accessed 26 Nov 2020

35. The OR Society. OR in Education. https://www.theorsociety.com/getinvolved/or-in-education/. Accessed 20 Oct 2020

36. INFORMS (2020) Resource Center. https://www.informs.org/Resource-Center. Accessed 20 Oct 2020

37. Pollock, SM (1994) editor. Operations Research and the Public Sector, Volume 6 - 1st Edition. Handbooks in Operations Research and Management Science. Elsevier Science

38. INFORMS. Public Sector OR. https://connect.informs.org/public-sectoroperations-research/home. Accessed 20 Oct 2020

39. INFORMS. O.R. \& Analytics for Policymakers. https://www.informs.org/Impact/O.R.-Analyticsfor-Policymakers. Accessed 20 Oct 2020

40. Brixius N (2015) Hole Hawg: OR's PR Problem. https://nathanbrixius.wordpress.com/2015/03/19/ hole-hawg-ors-pr-problem/. Accessed 02 June 2020

41. Rothberd E (2020) Imagine a World without Mathematical Optimization. https://www.gurobi.com/ resource/imagine-a-world-without-mathematicaloptimization/. Accessed 02 June 2020

42. Lübbecke M (2015) Are we too complicated? https://mluebbecke.wordpress.com/2015/03/23/are-wetoo-complicated/. Accessed 02 June 2020

43. Olson R (2015) Computing the optimal road trip across the U.S. http://www.randalolson.com/2015/03/08/ computing-the-optimal-road-tripacross-the-u-s/. Accessed 07 June 2020

44. Dantzig GB, Fulkerson DR, Johnson SM (1954) Solution of a largescale Traveling-Salesman Problem. Operations Research 2:393-410

45. The Washington Post (2015) A data genius computes the ultimate American road trip. https://www. washingtonpost.com/news/wonk/wp/2015/03/10/a-datagenius-computes-the-ultimate-americanroad-trip/. Accessed 07 June 2020

46. Applegate DL, Bixby RE, Chvat'aal V, Cook WJ (2006) The Traveling Salesman Problem: A Computational Study. Princeton University Press ISBN 9780691129938. http://www.jstor.org/stable/j.ctt7s8xg

47. Bixby R (2020) Mathematical Optimization: Past, Present and Future (Part 3). https://www.gurobi.com/ resource/mathematical-optimization-pastpresent-and-future-part-3/. Accessed 12 June 2020

48. Steenrod NE, Halmos PR, Schiffer MM, Dieudonne JA (1973) How to Write Mathematics. American Mathematical Society. ISBN 9780821800553. https://books.google.it/books?id=Qj0PAQAAMAAJ

49. Goulet C, Lamontagne M (2018) To Reach a Wider Audience, Simplify Your Science. Seismological Research Letters, 89(2A):677 ISSN 0895-0695. https://doi.org/10.1785/0220180003

50. Scharrer L, Rupieper Y, Stadtler M, Bromme R (2017) When science becomes too easy: Science popularization inclines laypeople to underrate their dependence on experts. Public Understanding of Science 26(8):1003-1018. https://doi.org/10.1177/0963662516680311

51. Lewenstein BV (2003) Models of public communication of science and technology

52. The Conversation (2020) Anna Nagurney, How coronavirus is upsetting the blood supply chain. https://theconversation.com/how-coronavirus-is-upsetting-the-bloodsupply-chain-133424. Accessed 12 June 2020

53. Nagurney A (2020) RENew: My Upcoming INFORMS Webinar: Blood, Sweat, and PPEs. http:// annanagurney.blogspot.com/2020/05/my-upcoming-informswebinar-blood-sweat.html. Accessed 12 June 2020

54. AIROYoung Researchers Chapter (2020) The AIROYoung Challenge. https://twitter.com/AIROyoung/ status/1226494501818191873. Accessed 21 Oct 2020

55. AIROYoung Researchers Chapter (2019) Instagram account. https://www.instagram.com/airoyoung/. Accessed 21 Oct 2020

56. AIROYoung Researchers Chapter (2016) Twitter account. https://twitter.com/AIROyoung. Accessed 21 Oct 2020

Publisher's Note Springer Nature remains neutral with regard to jurisdictional claims in published maps and institutional affiliations. 